Volume 9, No.4, July - August 2020

International Journal of Advanced Trends in Computer Science and Engineering

Available Online at http://www.warse.org/IJATCSE/static/pdf/file/ijatcse319942020.pdf

https://doi.org/10.30534/ijatcse/2020/319942020

\title{
Information Technologies for Managing of the Plants' Condition on the Example of Photosynthesis' Online Monitoring
}

\author{
Serhii Lienkov ${ }^{1}$, Larysa Komarova ${ }^{2}$, Anastasiia Bernaz ${ }^{3}$, Andrii Diachuk ${ }^{4}$, Nataliia Lytvynenko ${ }^{5}$, \\ Igor Tolok ${ }^{6}$ \\ ${ }^{1}$ Research Center, Military Institute of Taras Shevchenko National University of Kyiv, \\ Kyiv, Ukraine, lenkov_s@ukr.net \\ ${ }^{2}$ Odessa National Academy of Telecommunications, Kyiv, Ukraine, lacosta_k@ukr.net \\ ${ }^{3}$ The University of British Columbia, Faculty of Art and Science, \\ Vancouver, Canada, bernazstasy1902@gmail.com \\ ${ }^{4}$ Ecology and Pedagogical Education of Khmelnytsky National University, \\ Khmelnitsky, Ukraine, dyachyk_ao@ukr.net \\ ${ }^{5}$ Research Center, Military Institute of Taras Shevchenko National University of Kyiv, \\ Kyiv, Ukraine,n123n@ukr.net \\ ${ }^{6}$ Chief of the Military Institute of Taras Shevchenko National University of Kyiv, \\ Kyiv, Ukraine, igortolok@72gmail.com
}

\begin{abstract}
In the article on the basis of the analysis of providing the population of the world with food, the task of creation of small-sized intellectual devices for express systems of control of conditions of development of food plants is set. Such control can be carried out both in laboratory conditions and in the on-line mode. The authors analyzed the known methods of tissue diagnostics of plants by sap, by lymph, by extract, etc. The methods used in the laboratory, first of all, as one of the advanced ones on the simulation of cellular modeling of photosynthesis in plant tissues are considered.

Portable intelligent devices based on the method of chlorophyll fluorescence were created, its functional scheme was developed and a working model was developed, an application software package was developed. This allows on-line control of the impact on plants of stress factors, frost, drought, dehydration, the level of soil fertilizers, herbicides, biological additives, environmental pollution by harmful emissions, viral and bacterial loads. The effectiveness of research is shown.
\end{abstract}

Key words: the express system of control of development nodes, simulation cell modeling, small-sized intelligent devices.

\section{INTRODUCTION}

The analysis of the state of food security in the world, made by the authors of the article, shows that countries and regions can be divided into the following groups:
- developed countries, that provide themselves and are the main exporters in the world (USA, Canada, Australia, Argentina, Ukraine, and some European countries);

- small countries, that actively export food (Finland, Hungary, Belgium, the Netherlands, Moldova, and others);

- countries experiencing shortages of these products (Japan, South Korea, Hong Kong), but able to purchase them through the sustainable development of other industries;

- countries, that barely meet their needs through their own production, including through the development of additional water and land resources through the development of advanced innovation and scientific and technological progress (India, China, South America, the Middle East, and Southeast Asia);

- countries, in which food security is constantly deteriorating and which are on the verge of crisis or tragedy (a number of African and Asian countries).

According to the World Bank, affordable food is a problem for more than two billion people worldwide. In more than 40 developing countries, more than $70 \%$ of wages are spent on food, while in developed countries only 15\% [1]. This is especially true of the last two groups of countries and regions. The problems such as drought, soil depletion, floods, global climate change in general, the conversion of traditional energy technologies to biofuels, and so on, are stalling agriculture.

These trends are well illustrated by the development of the food industry in the poorest countries, which prefer to grow more profitable crops such as rapeseed, palm oil and so on. Therefore, the availability of a sufficient number of food products on the market of these countries depends on imported supplies, not on their own production. At the same 
time, the crisis has forced economically developed countries to invest heavily in food production, the profitability of which is growing rapidly. This also affected the cost of food. Based on this, the development of agricultural productivity in our countries is of paramount importance.

One of the basic elements of resource-saving technologies in agriculture is the so-called "precision" agriculture, namely the management of crop productivity taking into account the intra-field variability of the environment in which these crops are grown [2].The purpose of such management is to obtain maximum yields in terms of optimizing the process of agricultural production, including resource savings (fertilizers, herbicides, biological additives). At the same time, there are real opportunities for the production of high-quality products while preserving the external natural environment.

Since crop production is the basis for the development of the entire food sector, food disaster prevention is one of the most pressing challenges today. Today, tissue diagnostics of plants are sufficiently developed, for example, express analysis of sections and juice according to G. S. Davtyan [3], analysis for the amount of nitrates, orthophosphates, potassium. Analysis of plant lymph by Sabinin D. A. [4], analysis of plant extract by K. L. Magnitsky [5], many other studies.

Besides, it should be noted that all these methods are outdated, they are time-consuming and cannot be used for online monitoring of plant development.

That is why the development of information technology, appropriate devices, and systems for monitoring and diagnosing plant development is devoted to a number of recent scientific studies in leading countries $[6,7]$.

Several articles, performed by the authors of this paper $[8,9]$, consider the possibility of remote sensing to control the quality of plants, their bacterial and fungal damage, exposure to stressful situations and more. Moreover, such means can be installed on the mobile intelligent devices, such as a helicopter $[10,11]$. However, these methods don't fully solve the problem, that sets in the paper. So this article is devoted to the development of tools for the rapid diagnosis of plant products based on photosynthesis control, software for data processing, methodological support, and assessment of plant conditions.

\section{METHODOLOGY}

Since rapid climate change does not always allow to optimize the application of fertilizers, pesticides, to control artificial irrigation, to predict yields, it is necessary to model the processes that occur in plants due to the influence of influencing factors. First of all, this applies to photosynthesis. Photosynthesis is a multi-step and very complex process, so its modeling focuses on individual parts of the process, in particular on the modeling of the Calvin cycle. There are many models of photosynthesis and its components, but none describes this process completely. In addition, it is important to confirm the simulation results by a field experiment, which can be based on the method of induction of chlorophyll fluorescence.

For effective use of the induction of chlorophyll fluorescence method and improvement of methods and technologies for diagnosing the condition of plants based on it, it is expedient to establish the connection of models of the photosynthesis process with the shape of the induction of chlorophyll fluorescence curve. We have considered some models of photosynthesis and the possibility of their use in combination with the method of induction of chlorophyll fluorescence for rapid assessment of plant conditions. The main source of energy for photosynthesis is the energy of the Sun. Plants use for the photosynthetic process no more than $2-5 \%$ of the received solar energy.

This energy is absorbed by certain cell structures, namely by a specialized association (organelle) - chloroplast. Chloroplasts contain thylakoids (formations), which in turn form their spatial structure, various enzymes involved in the chemistry of plant uptake of $\mathrm{CO} 2$.In terms of chemical composition as a percentage of dry matter, most chloroplasts consist of proteins (30-60\%), lipids (20-40\%), DNA (0.01-0.02\%), RNA (0.5 $3.5 \%)$. ), minerals (6-10\%) and pigments - chlorophyll (5-9\%), carotenoids (4-5\%) [10]. A pigment is a compound (complex molecule) that absorbs light in the visible region of the spectrum (400-700 nm). Depending on the spectral composition of the absorbed light, the pigments acquire a color - green, yellow, red, and others. There are three classes of photosynthetic pigments - chlorophyll, carotenoids, and phycobilins. The most important role is played by chlorophyll, a pigment that absorbs light in the red and blue bands of the spectrum, while in green - light is reflected. Currently, more than ten types of chlorophyll are known, but the main pigment is chlorophyll a. The chromatographic analysis revealed that chlorophyll a has a molecule $\mathrm{C}_{55} \mathrm{H}_{72} \mathrm{O}_{5} \mathrm{~N}_{4} \mathrm{Mg}$.

When light is absorbed, chlorophyll has two maxima with the peaks at $428-430 \mathrm{~nm}$ and $660-663 \mathrm{~nm}$ [13]. The optical properties of chlorophyll are due to its structure. The pigment is characterized by a clear alternation of double and single bonds. Each carbon atom contains eight valence electrons. Between each pair of electrons, $\mathrm{C}$ is a pair of electrons that forms a $\sigma$-bond. In addition, there is a pair of $\pi$-electrons that can move along the entire carbon chain (resonance phenomenon). Due to the resonance of chlorophyll, molecules get additional stability [12].

Paired electrons are easily excited by light quanta. The energy of such excitation is easily provided by solar radiation in the light spectre of 380-720 nm. Chlorophyll (unlike other pigments) has an additional ability to absorb light. Each nitrogen atom has three pairs of electrons that are bound to magnesium. These electrons also have the ability to absorb light. 
Let us have a look at the general equation of photosynthesis, the equation of which is as follows:

$6 \mathrm{CO}_{2}+12 \mathrm{H}_{2} \mathrm{O}$ - light, chlorophyll $\rightarrow \mathrm{C}_{6} \mathrm{H}_{12} \mathrm{O}_{6}+6 \mathrm{O}_{2}+6 \mathrm{H}_{2} \mathrm{O}$.

This reaction can also be described by two redox reactions, one of which involves the photodissociation of water: $6 \mathrm{CO}_{2}+12 \mathrm{H}_{2} \mathrm{O}$ light, chlorophyll $\longrightarrow \mathrm{C}_{6} \mathrm{H}_{12} \mathrm{O}_{6}+6 \mathrm{O}_{2}+6 \mathrm{H}_{2} \mathrm{O}$;

and the second is the reduction of $\mathrm{CO}_{2}$ to hydrocarbons, but without the participation of solar energy quanta: $\mathrm{CO}_{24} \mathrm{H}+4 \mathrm{e}^{-} \rightarrow\left(\mathrm{CH}_{2} \mathrm{O}\right)_{4}+\mathrm{H}_{2} \mathrm{O}$.

Thus, photosynthesis consists of two phases: dark and light. In the first (light) phase, high-energy electrons are formed; in the second (dark) phase, the energy products of the first phase are used to restore $\mathrm{CO}_{2}$ to carbohydrates. The main locations of photosynthesis, anatomically adapted to its conduct, are the leaves of the higher plants.

Light phase of photosynthesis. Photosynthesis is, above all, a physical process. It begins with the absorption of electromagnetic energy of solar quanta in the form of excited electrons of chlorophyll (the process of accumulation and stabilization). Currently, the main hypothesis of energy transportation is the hypothesis of inductive resonance, which is confirmed by the phenomenon of fluorescence.

In photosynthetic cells, fixed $\mathrm{CO}_{2}$ is converted into 2 main carbohydrates - sucrose and starch. Sucrose is transferred to areas of rapid growth and to the developing seeds. Starch accumulates in chloroplasts in the form of grains, and then it turns into sucrose and is removed from the cells. Fructose-6-phosphate is used for starch synthesis, which is removed from the Calvin cycle and converted first to glucose-6-phosphate, then to glucose-1-phosphate and then to ADP-glucose, which is later converted to amylose. Sucrose is synthesized in the cytoplasm.

As already mentioned, there is a large number of models of photosynthesis and its components. Let us take a look at some of the most suitable for use in conjunction with the induction of chlorophyll fluorescence method when creating an express analyzer.

Computer simulation of photosynthesis using the E-CELL system (authors: Emily Wang, Yoichi Nakayma, Masaru Tomita). The Bioinformatics Laboratory at Keio University (Tokyo, Japan) has developed the E-CELL software package for the simulation of cell modeling. This package is distributed under the GPL license [14] and is made for Linux operating systems.

With the help of this package, a prototype of the Calvin cycle model (dark phase of photosynthesis) was created, as well as an extended model for modeling the entire metabolic flow of the cell for light reactions. Enzyme reactions and parameters in this model are based on mathematical models of G. Pettersson and U. Ryde-Pettersson [15], as well as A. Laisk [16]. The obtained models [17] allow us to analyze the differences in the regulation of metabolism of various photosynthetic systems and their responses to environmental changes. It should be noted that the E-CELL modeling package is a modern and promising tool for modeling biological objects and can be used in conjunction with the induction of chlorophyll fluorescence method.

There are several other models, first of all, the following:

- model of photosynthesis dynamics (authors: Marcelo Shoey de Oliveira, Carlos Eduardo Novo Gatts, Affonso Guidao Gomes, and Yelion Vargas, 2001) [18];

- mathematical model of the Calvin photosynthesis cycle (authors: GostaPettersson, Ulf Ryde-Pettersson, 1988) [15];

- modeling and control of the process of photosynthesis (authors: Magk G. Pollman, David A. Fell, Simon Thomas, 2000) [19].

The last paper considers the dynamic and stationary behavior of the computer model of the Calvin chloroplast cycle reactions, including the synthesis and cleavage of starch, as well as the export of triphosphate. One of the main differences from the previous models is the assumption that none of the reversible reactions are in equilibrium. The model can detect alternative stationary states of low or high flux assimilation flux with hysteresis in transitions between stationary states caused by external factors such as the presence of phosphate and changes in light intensity.

Kinetic model of the photosystem II of higher plants (G.V. Lebedeva, N.E. Belyaeva, G.Yu. Riznichenko, A.B. Rubin, O.V. Dyomin, 2000) [20, 21]. These scientists proposed a detailed kinetic model of the catalytic cycle of Photosystem II higher plants, in which the theoretical calculation and construction of the induction of chlorophyll fluorescence curves at different values of the model parameters were performed. To calculate the fluorescence intensity of chlorophyll, a ratio that contains the concentrations of fluorescent states of Photosystem II and their dependence on the components of the electrochemical potential on the thylakoid membrane was proposed.

Within the framework of this model, separate fragments of the induction of chlorophyll fluorescence curve can be constructed: it is not yet possible to reproduce the real induction of chlorophyll fluorescence curve in full with the help of this model. Despite some limitations, this model correlates well with the induction of chlorophyll fluorescence method and can be used to develop generalized techniques for fluorimeters and forms the basis for our development of an intelligent device for automated control of photosynthesis.

\section{RESULT AND DISCUSSION}

The word "data" is plural, not singular. The subscript for the Analysis of existing models of photosynthesis will allow you to choose the most suitable of them, namely, the method of induction of chlorophyll fluorescence. Let's focus on the features that allow you to use this method in the construction of a portable computer device for rapid diagnosis of plants and the impact on their condition of environmental factors (temperature, humidity, soil composition, air pollution, groundwater, soil, fertilizers, etc.). 
There are three main ways to realize the energy of light quanta absorbed by chlorophyll molecules: photochemical reaction, thermal dissipation and fluorescence. All these processes are competitive, as a result of which a change in the efficiency of one of them leads to a change in the other two, and a decrease in the efficiency of, for example, a photosynthetic process can increase the efficiency of fluorescence and thermal dissipation. At the initial moment of time, all channels of photosynthetic electron transfer are open and the maximum energy of excited electrons goes to the photosynthetic process. During this period, the fluorescence of chlorophyll is minimal and its intensity on the Kautsky's curve is denoted by $F_{0}$. The transition $F_{1}-F_{0}$ is associated with a decrease in electron transport. The transition $F_{1}-F_{0}$ is observed, for example, with a short period of thermal adaptation. The whole section $F_{1}-F p$ is called the fast phase of fluorescence. The slow phase of induction of chlorophyll fluorescence represents all induction transitions after reaching the peak $P$.

The possibility of estimating the condition of plants by changing the shape of the Kautsky's curve has been confirmed experimentally. Examples of changes in the shape of this curve under the influence of external factors are given below.

Increasing the ambient temperature relative to the optimum for a given plant species reduces the difference $F_{v}=F_{p}-F_{0}$. The reason is a decrease in the activity of the electron transport chain or the light stage of photosynthesis. As the temperature rises to the level of destruction $\left(45-50^{\circ} \mathrm{C}\right)$, the level of intensity $\mathrm{F}_{0}$ noticeably increases. In the selection process on these indicators, you can quickly select plant varieties that are resistant to high temperatures.

The decrease in ambient temperature relative to the optimal for this species of plants also leads to a decrease in the value of $F_{v}=F_{p}-F_{0}$, which is due to the inhibition of photochemical activity of Photosystem II. The ratio $\left(F_{1}-F_{0}\right) / F_{V}$ increases. On these grounds, you can select cold-resistant plants.

Water deficiency leads to a decrease in the difference $F_{p}-F_{0}$ in proportion to the decrease in the water potential of the leaves. The most probable reason is the slowdown in the recovery of the primary acceptor of Photosystem II due to the inhibition of oxygen release, inhibition of intersystem electron transport. According to this indicator, you can select drought-resistant specimens of plants.

The portable device developed on the basis of the methodology described above allows to register fluorescence of the leaf device of a plant and are used for an estimation of productivity of crops. Information in the form of a chlorophyll fluorescence induction curve is displayed on the monitor of the device. The shape of this curve can be used to assess the physiological state of the photosynthetic process as a whole and the kinetics of its individual parts. Changes in the links of the photosynthetic process lead to a change in the shape of the chlorophyll fluorescence induction curve. By changing the shape of individual sections of this curve predict the impact of individual environmental factors on the condition of the plant. The functional system of the portable intelligent device is shown in Fig.1. A leaf of the plant is placed between the plates of the remote optical sensor of the device.

Part of the sheet between the plates is isolated from outside light and undergoes dark adaptation for 3-5 minutes. The remote sensor illuminates part of the surface of the sheet plate with a diameter of $5 \mathrm{~mm}$ with blue light. Under the action of artificial light in the chlorophyll of the irradiated leaf, fluorescence is excited in the red region of the spectrum. The optical fluorescence signal of chlorophyll through the red filter is fed to the photodetector of the sensor and converted into an equivalent electrical signal. Next, the analog electrical signal is converted in the base unit of the device into a digital code and processed by a microprocessor, which is configured to analyze the signal according to a specific method.

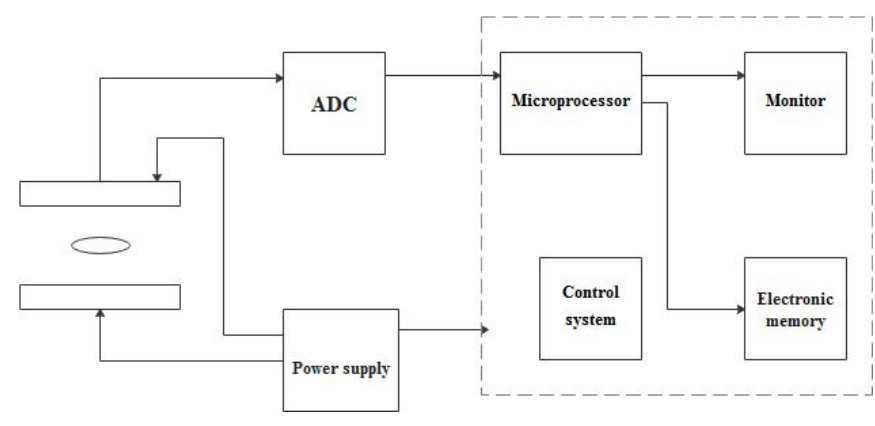

Figure 1: Functional Diagram of a Portable Intelligent Device

Measurements are made in the natural environment. Operating conditions of the fluorometer: ambient temperature from $0{ }^{\circ} \mathrm{C}$ to $55^{\circ} \mathrm{C}$; atmospheric pressure from $84 \mathrm{kPa}$ to 107 $\mathrm{kPa}$; relative humidity up to $98 \%$ at a temperature of $25^{\circ} \mathrm{C}$. To assess the state of the photosynthetic apparatus of the plant use the processing of data on the fluorescence intensity of chlorophyll over time, followed by processing and selection of characteristic points. These signs can detect and assess the effect of the following stressors on plant life: frost, drought, dehydration; application of fertilizers, herbicides, biological additives to the soil; pollution of the environment with harmful emissions; viral and bacterial loads, etc.

In addition, the device allows to optimize the norms of artificial irrigation, the amount of fertilizers, chemical plant protection products, to select the optimal technological methods of growing cultivated plants, to ensure the management of agricultural production. 


\section{CONCLUSION}

In this article, a number of methods and ways to control the conditions of development of food plants is reviewed. Based on this, it is proposed to use online control of the development of food crops with the method of induction of chlorophyll fluorescence in plant cells. A normative device for rapid analysis of plant condition using simulation of cellular modeling of photosynthesis has been developed.

The efficiency of the device that is operatively used directly on places of plants growth is shown. Factors are studied, and a software product is developed to adapt the intelligent device on the effects of stress factors, frosts, drought, dehydration, soil fertilizers, herbicides, biological additives, environmental pollution by harmful emissions, viral and bacterial loads on plants.

\section{REFERENCES}

1. A. V. Saveleva. The role of the food problem in the modern world economy, HSE Journal of Economics, Moscow, vol. 3, pp. 524-539, 2013.

2. V. V. Yakushev. Precision Agriculture: Theory and Practice. St. Petersburg: FSBSI ARI, 364 p., 2016.

3. G. S. Davtian, T. T. Vardanian. The flow of substances with precipitation in the territory of the Armenian SSR. Reports of the SRI of Agrochemical Problems and Hydroponics of the Academy of Sciences, Armenia SSR, Yerevan, vol. 9, pp. 48-52, 1970.

4. V. V. Zirling. Diagnosis of nutrition of agricultural crops: Handbook. Moscow, Agropromizdat, 236 p., 1990.

5. Analysis of extracts from plants according to Magnitsky, available:

http://agrohimija24.ru/agrohimicheskie-metody/1951-a naliz-vytyazhek-iz-rasteniy-po-magnickomu.html.

6. R. Hendi Ristanto, M. Miarsyah, D. Robiatun Muharomah, T. A. Astuti, S. Aini, A. Indaryanti Prihatin. Light-Board: Simple Media to Learn Photosynthesis Concepts. International Journal of Advanced Trends in Computer Science and Engineering, Vol. 9, No1, pp. 299-303, 2020, https://doi.org/10.30534/ijatcse/2020/45912020.

7. C. \& Raju Sughantan,, RLN. Differences in the Board of Education and its Impact in the Writings of Engineering Graduates. International Journal of Advanced Trends in Computer Science and Engineering, Vol. 8(5), pp. 2677-2679, 2019, https://doi.org/10.30534/ijatcse/2019/1238512019.

8. N. Pasichnyk, S. Lienkov, S. Shvorov, L. Komarova, D. Komarchuke, O. Opryshko. The use of UAVs with the "Slantrange" sensor system to estimation crop safety base on technological stress and intoxication of plants, Information Security Published Since, Sofiya, Vol. 45, pp. 21-33, 2020.
9. S. A. Shvorov, N. A. Pasichnyk, S. D. Kuznichenko, I. V. Tolok, S. V. Lienkov, L. A. Komarova. Using UAV during Planned Harvesting by Unmanned Combines, IEEE 5th International Conference Actual Problems of Unmanned Aerial Vehicles Developments, APUAVD, pp. 252-257, 2019.

10. S. Lienkov, A. Myasische, O. Banzak, Y. Husak, I. Starynski. Use of rescue mode for UAV on the basis of STM32 microcontrollers, International Journal of Advanced Trends in Computer Science and Engineering, Vol. 9, No. 3, available at:

http://www.warse.org/IJATCSE/static/pdf/file/ijatcse15 6932020.

11. V. Lysenko, Y. Gunchenko, S. Shvorov, S. Lenkov, S. Kuznichenko, E. Lenkov. Methodological Bases of Construction of Intensive Training Flight Simulators of Aircrews, Proceedings 5th International Conference "Methods and Systems of Navigation and Motion Control", Kyiv, pp. 198 - 203, 2018.

12. D. Y. Korneev. Information possibilities of chlorophyll fluorescence induction method, Kyiv, Altapres, 188 p., 2002.

13. Quinone, available at http://nts.sci-lib.com/article0005313.html.

14. GNU operating system, available at http://creativecommons.org/licenses/GPL/2.0/.

15. Pettersson Gosta, Ryde-Pettersson Ulf. A mathematical model of the Calvin photosynthesis cycle, Eur.Biochem., 1988, №175, pp. $661-672$.

16. A. Laisk, H. Eichelmann, V. Oja, A. Eatherall, D. Walker. Mathematical model of the carbon metabolism in photosynthesis difficulties in explaining oscillations by fructose 2,6-bisphosphate regulation, London, №227, pp. 281 - 302, 1986.

17. E. Wang, Y. Nakfyama, M. Tomita. Computer Modeling of Photosynthesis Using the E-CELL System, Genome Informatics, №11, pp. 458 - 459, 2000.

18. Marcelo Shoey de Oliveira Massunaga, Carlos Eduardo Novo Gatts, Helion Vargas. A simple model for the dynamics of photosynthesis. ANALYTICAL SCIENCES APRIL, №17, Special Issue, pp. 29 - 30, 2001.

19. Mark G. Simon Thomas. Modeling photosynthesis and its control, J. of Experimental Botany, №51, GMP Special Issue, pp. $319-328$.

https://doi.org/10.1093/jexbot/51.suppl_1.319

20. G. Y. Reznichenko. Mathematical models of the primary processes of photosynthesis. Results of science and technology. Biophysic Series, Moscow, №31, 162 p., 1991.

21. G. V. Lebedeva, N. E. Beliaeva, G. Y. Reznichenko, A. B. Rubin, O. V. Demin. Kinetic model of photosystem II in higher plants, Journal of Physical Chemistry, №74, pp. 1874-1883, 2000. 